\title{
Intercalation Compounds involving Inorganic Layered Structures
}

\author{
VERA R. L. CONSTANTINO, CÉSAR A. S. BARBOSA, MARCOS A. BIZETO and PATRÍCIA M. DIAS
}

Departamento de Química Fundamental, Instituto de Química, Universidade de São Paulo Cx. Postal 26077 - 05513-970 São Paulo, SP, Brazil

Manuscript received on September 8, 1999; accepted for publication on September 15, 1999; presented by José M. RIVEROS

\begin{abstract}
Two-dimensional inorganic networks can shown intracrystalline reactivity, i.e., simple ions, large species as Keggin ions, organic species, coordination compounds or organometallics can be incorporated in the interlayer region. The host-guest interaction usually causes changes in their chemical, catalytic, electronic and optical properties. The isolation of materials with interesting properties and making use of soft chemistry routes have given rise the possibility of industrial and technological applications of these compounds. We have been using several synthetic approaches to intercalate porphyrins and phthalocyanines into inorganic materials: smectite clays, layered double hydroxides and layered niobates. The isolated materials have been characterized by elemental and thermal analysis, X-ray diffraction, surface area measurements, scanning electronic microscopy, electronic and resonance Raman spectroscopies and EPR. The degree of layer stacking and the charge density of the matrices as well their acid-base nature were considered in our studies on the interaction between the macrocycles and inorganic hosts.
\end{abstract}

Key words: intercalation compounds, layered double hydroxides, smectite clays, layered niobates.

\section{INTRODUCTION}

Solid state inclusion chemistry involves almost exclusively inorganic host-guest compounds. Nanoporous inorganic hosts as zeolites and clays can incorporate simple cationic ions, large ionic species as Keggin ions, organic ions or molecules, coordination compounds or organometallics. Considering two-dimensional inorganic networks, graphite and clays were the first layered hosts having the intracrystalline reactivity explored in academic and technological works (Lagaly \& Beneke 1991). The interest in the intercalation process increased considerably after 1960 and have included other classes of layered materials as, for example, metal(IV) phos-

Correspondence to:

Vera R. L. Constantino

E-mail: vrlconst@quim.iq.usp.br phates and phosphonates, transition metal dichalcogenides, transition metal oxyhalides, alkali-transition metal oxides and hydrotalcite-type anionic clays (Alberti \& Costantino 1996).

The attention given to intercalated layered compounds can be attributed mainly to the fact that the host - guest interaction often changes significantly their chemical, catalytic, electronic, optical and mechanical properties. The isolation of materials with interesting properties and use of soft chemistry routes have given rise to the possibility of industrial and technological applications of intercalated compounds as components in electrochemical devices (batteries, sensors etc.) and as heterogeneous catalysts (Alberti \& Costantino 1996). Concerning the occurrence of selective chemical reactions in the in- 
terlayer region of inorganic hosts containing reactive guest species, transition metal complexes of macrocyclic ligands as porphyrins and phthalocyanines (synthetic models that mimic natural enzymatic systems) have been intercalated and evaluated for catalytic purposes (Rives \& Ulibarri 1999, Chibwe et al. 1996, Ukrainczyk et al. 1995, Bedioui 1995). Some studies have shown that the confinement of these reactive species into two-dimensional frameworks can improve their catalytic activity and durability.

We have been using several synthetic approaches to intercalate macrocycle species into inorganic layered materials (cationic clays, layered double hydroxides and layered niobates). The intercalated solids have been characterized by elemental and thermal analysis, X-ray diffraction (XRD), surface area measurements, scanning electronic microscopy, electronic (absorption and emission) spectroscopy, resonance Raman spectroscopy and EPR. The degree of layer stacking and the charge density of the inorganic matrices as well as their acid-base nature were considered in our studies concerning the interaction between macrocyclic species and the inorganic hosts. Some details about the layered structures and some data obtained in our research work are presented as follow.

The clay minerals are a class of lamellar solids that have a remarkable ability to adsorb or intercalate cationic or neutral molecules between the layers. Their structure consists of tetrahedra and octahedra sheets, joined together by sharing oxygen atoms (Mott 1988). The most common structure for cationic clays is based on a octahedral sheet sandwiched between two tetrahedral sheets (TOT layers), as shown in Fig. 1. The substitution of structural cations by others with lower valency leaves a charge deficiency on the layers, neutralized by species adsorbed or located in the interlayer region. The first studies concerning porphyrin adsorption on clays were stimulated by the fact that these macrocycles are the most important biological markers in sediments and sedimentary rocks (Bergaya \& Van Damme 1982).

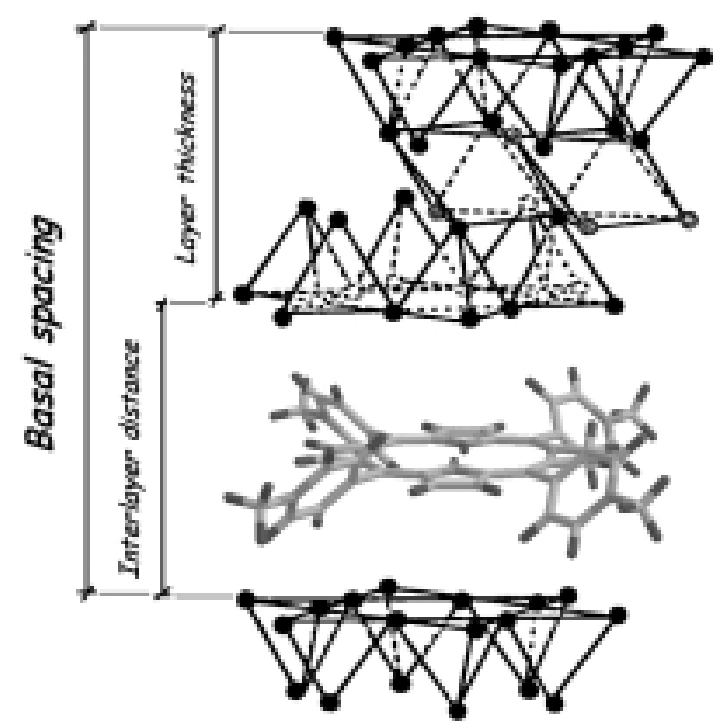

Fig. 1 - Schematic representation of a 2:1 layered silicate intercalated with a cationic meso-substituted porphyrin (TMPyP).

We have studied the interaction between some smectite clays and tetramethylpyridylporphyrins (free base, TMPyP, and the cobalt complex, CoTMPyP). K10, KSF and Swy2 are naturally occurring montmorillonites while Syn1 is a synthetic one. FHT and Laponite are synthetic hectorites (in FHT, the hydroxyl groups are substituted by fluoride). The clay samples investigated show some different structural parameters as the cation exchange capacity (CEC), the occupancy of octahedral sites (di- or trioctahedral minerals) and kind of layer aggregation (face-to-face, edge-to-face). All the clay samples containing porphyrins were prepared by ion exchange reaction in a water suspension.

The basal spacing data obtained for all the clay samples saturated with TMPyP $\left(\mathrm{d}_{001} \sim 14-15 \AA\right)$, except for FHT, suggest a flat orientation of the porphyrin ring relative to the host layers, as can be seen in Fig. 1. The higher CEC of FHT compared to the CEC of all the other layered silicates causes the TMPyP intercalation in a tilted orientation $\left(\mathrm{d}_{001} \sim 18 \AA\right)$. K10 and KSF samples saturated with TMPyP are green while the FHT one is brown. Diffuse reflectance spectra of these samples show 
that the Soret and Q bands are red shifted after interaction with the clays when compared to the free TMPyP or the protonated form $\left(\mathrm{H}_{2} \mathrm{TMPyP}\right)$. The bands at ca. 430 and $468 \mathrm{~nm}$ in the clays electronic spectra were assigned to non-protonated and protonated TMPyP, respectively. Resonance Raman data support this attribution and also showed the $v_{2}$ mode (ca. $1550 \mathrm{~cm}^{-1}$ ) to be the most sensitive peak to protonation. In the electronic spectra of FHT containing 10, 50 and $100 \%$ of CEC balanced by CoTMPyP, the bands are red shifted even when a small amount of porphyrin is used, suggesting that the electronic levels of the macrocycle are more affected by the interaction with the clay than by orientation or possible porphyrin distortions in the gallery region. The resonance Raman spectra obtained for the CoTMPyP samples present only minor shifts in peak positions and band width (Dias et al. 1998).

Layered double hydroxides (LDHs, also named hydrotalcite-type anionic clays) are another class of layered inorganic host that have been used in the intercalation chemistry area. LDHs present the general formula

$$
\left[\mathrm{M}^{\mathrm{II}}\left({ }_{1-x}\right) \mathrm{M}^{\mathrm{III}}{ }_{x}(\mathrm{OH})_{2}\right]\left(\mathrm{A}^{n-}\right)_{x / n} \cdot \mathrm{zH}_{2} \mathrm{O}
$$

where $\mathrm{M}^{\mathrm{II}}$ and $\mathrm{M}^{\mathrm{III}}$ represent di and trivalent cation octahedrally coordinated to hydroxyl ions and $\mathrm{A}^{\mathrm{n}-}$ is the interlayer anion. These octahedra are connected to each other by edge sharing to form an infinite sheet. LDHs and their calcined products have been used as catalysts and catalyst supports in organic synthesis; environmental adsorbents and/or anionic exchangers; precursors to synthesize advanced ceramics; modified electrodes and in the pharmaceutical and medicine area (Trifirò \& Vaccari 1996).

To evaluate the catalytic properties of LDHs intercalated materials, we have intercalated cobalt(II) tetra(4-sulfonatophenyl)porphyrin (CoTPhsP) and cobalt(II) tetrasulfophthalocyanine (CoPcTs) into a LDH of hydrotalcite-type and also supported these macrocycles on the external surface of the LDH $\left(\mathrm{CO}_{3}^{2-}\right.$ occupies the interlayer region). The intercalated compounds were synthesized through three methods: (i) double hydroxide coprecipitation in the

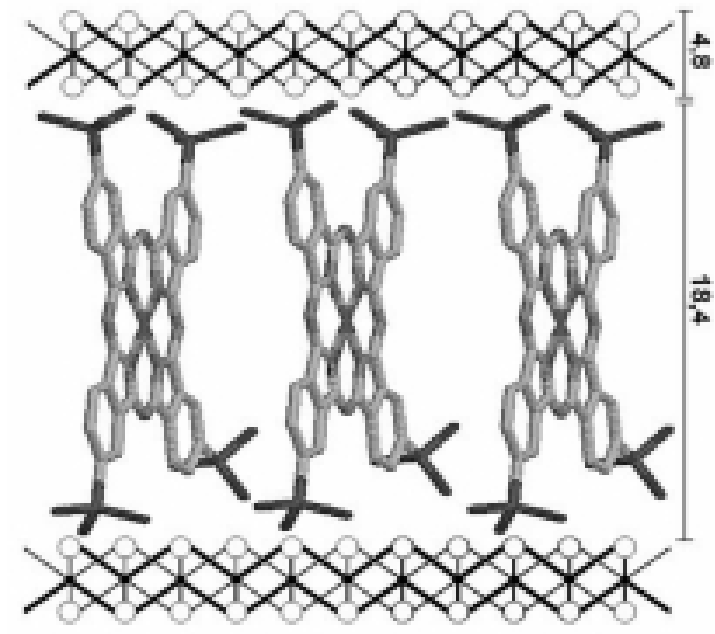

Fig. 2 - Schematic representation of a layered double hydroxide intercalated with an anionic metallophthalocyanine (MPcTs). Open circles $=\mathrm{OH}$ groups; dark circles $=$ metal ions .

presence of the macrocycle, (ii) structure reconstruction of the mixed oxides obtained by thermal decomposition of LDH phase containing volatile ion; (iii) thermal decomposition of carbonate-containing phase in a polyol media. The effect of the materials textural properties and the macrocycle arrangement in the LDH interlayer region was evaluated by carrying out the hydrogen peroxide decomposition reaction (catalase-like activity) (Barbosa 1999).

The macrocycle intercalation between LDHs layers was confirmed by XRD data: the basal spacing of the carbonate precursor $\left(\mathrm{d}_{003} \sim 8 \AA\right)$ increases to approximately $23 \AA$ in the hosts intercalated with phthalocyanine or porphyrin. The surface area data suggested that the macrocycle intercalated solids have no microporous. LDHs samples intercalated with CoPcTs seem to be aggregated in the interlayer space taking into account the diffuse reflectance spectra profile. The characterization data suggest that the plane of macrocycles were perpendicular to the plane of the LDH layers and closely packed into interlamelar space as shown in Fig. 2.

The confined metallated macrocycle compounds showed catalase-like activity. However, the 
catalytic activity of the intercalated materials was distinct for each macrocycle system tested. The kinetic curves for molecular oxygen evolution in the hydrogen peroxide dismutation reaction $(\mathrm{pH} 7.8$ and $\mathrm{T}=30^{\circ} \mathrm{C}$ ) showed that CoTPhsP in homogeneous media was partially deactivated while the immobilized one (heterogeneous condition) was more active during the whole reaction time. It should be pointed out that the porphyrin is stabilized in the presence of hydrogen peroxide when it is immobilized in LDH. Unlike CoTPhsP, the pure phthalocyanine species in homogeneous or heterogeneous media are not degraded by $\mathrm{H}_{2} \mathrm{O}_{2}\left(\mathrm{pH} 9.6\right.$ and $\left.\mathrm{T}=30^{\circ} \mathrm{C}\right)$. The $\mathrm{LDH}-$ immobilized phthalocyanine exhibited better catalytic performance than the free macrocycle.

Layered niobates have a semiconducting character that have been explored to achieve the water splitting to $\mathrm{H}_{2}$ by photocatalysis and to promote photoinduced electron transfer process between the host and intercalated guest species (Ogawa \& Kuroda 1995). Incorporation of bulky ions into the interlayer space of niobates is not easy to perform due to their high layer charge densities. We have reported for the first time a synthetic procedure to intercalate macrocycle species (TMPyP, in the case) into a $\mathrm{KNb}_{3} \mathrm{O}_{8}$ derivative host (Bizeto et al. 1999). The porphyrin intercalation into the layered material containing potassium ions or even in its $\mathrm{H}^{+}$exchanged form does not occur. The proposed method is based on the expansion of the interlayer region through an acid-base reaction between the proton exchanged form of the matrix and an nbutylamine.

The calculated formula for the porphyrin intercalated compound was

$$
[\mathrm{TMPyP}]_{0.14} \mathrm{H}_{0.44} \mathrm{Nb}_{3} \mathrm{O}_{8} .2 .5 \mathrm{H}_{2} \mathrm{O}
$$

based on elemental and thermogravimetric analysis. The basal spacing variation $\left(\Delta \mathrm{d}_{020}\right)$ of $14.3 \AA$ is consistent with an inclined orientation of the macrocycle relative to the host lamellar plane. Fig. 3 shows a schematic representation of the porphyrin intercalated compound.

XRD pattern of TMPyP confined into the lay-

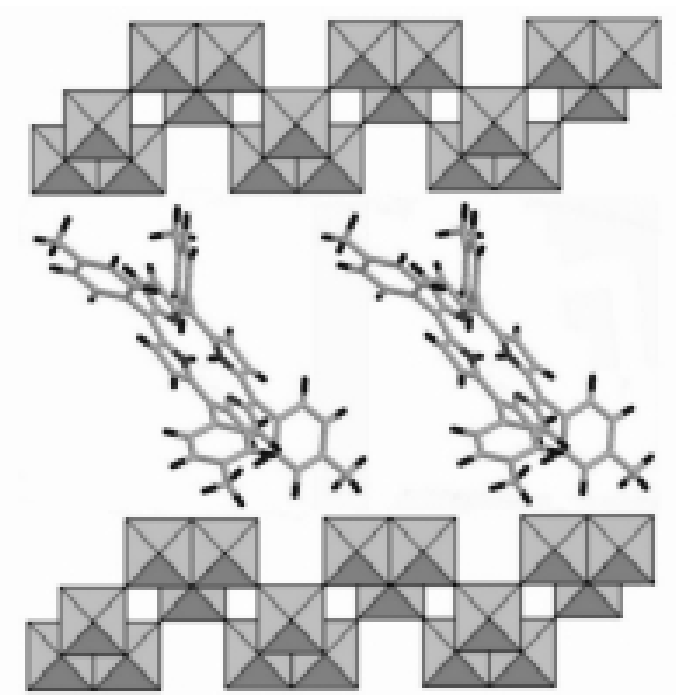

Fig. 3 - Schematic representation of the layered niobate $\left[\mathrm{Nb}_{3} \mathrm{O}_{8}\right]^{-}$intercalated with a cationic meso-substituted porphyrin (TMPyP). Squares represent $\left[\mathrm{NbO}_{6}\right]$ octahedral units (distortions are not shown).

ered niobate shows only the (0k0) peaks which could indicate the occurrence of an exfoliation process when the n-butylamine intercalated material was stirred in water. We can propose that the stirring step provokes the solid delamination and the formation of colloidal particles that upon contact with the TMPyP solution, causes the layer stacking to incorporate the guest species.

The electronic absorption spectrum of the TMPyP intercalated sample showed that the Soret and $Q$ bands practically were not shifted when compared to the spectrum of the macrocycle in water. This result indicates that TMPyP is not protonated in the interlayer region as has been observed in studies with smectite clays. Resonance Raman spectrum also corroborates the assumption of the presence of the non-protonated species in the host structure.

Good results have also been obtained using the synthetic method above described to intercalate TMPyP into the $\mathrm{K}_{4} \mathrm{Nb}_{6} \mathrm{O}_{17}$ layered host or into the layered perovskite series of general formula

$$
\mathrm{K}_{1-x} \mathrm{La}_{x} \mathrm{Ca}_{2-x} \mathrm{Nb}_{3} \mathrm{O}_{10} \quad(0 \leq x \leq 1) .
$$




\section{ACKNOWLEDGMENTS}

We are grateful to Profs. Ana Maria da Costa Ferreira and Dalva Lúcia Araújo de Faria (Instituto de Química - USP) for the fruitful discussions and collaboration. The financial support and fellowships from Fapesp and CNPq are also acknowledged.

\section{REFERENCES}

Alberti G \& Costantino U 1996. Layered Solids and Their Intercalation Chemistry. In: Alberti G $\&$ BeIn T. eds. Solid State Supramolecular Chemistry: Two and Three-Dimensional Inorganic Networks. New York, Pergamon, Vol. 7, Ch. 1, p.1-23.

Barbosa CAS 1999. Preparation and Characterization of Layered Double Hydroxides Intercalated with Macrocycle Metallated Species. São Paulo, 127p. (Dissertation, Universidade de São Paulo).

Bedioui F 1995. Zeolite-encapsulated and Clayintercalated Metal Porphyrin, Phthalocyanine and Schiff-Base Complexes as Models for Biomimetic Oxidation Catalysts: An Overview, Coord Chem Rev 144: $39-68$.

Bergaya F \& Van Damme H 1982. Stability of metalloporphyrins adsorbed on clays: a comparative study. Geochim Cosmochim Acta 46: 349-360.

Bizeto MA, Faria DLA \& Constantino VRL 1999. Organic-Inorganic Hybrid Material Synthesized by Porphyrin Intercalation into a Layered Niobate Host Matrix. J Mater Sc Lett 18: 643-646.
Chibwe M, Ukrainczyk L, Boyd SA \& Pinnavaia TJ 1996. Catalytic Properties of Biomimetic Metallomacrocycles intercalated in Layered Double Hydroxides and Smectite Clays: the importance of edge-site access, J Molec Catal 113A: 249-256.

Dias PM, Constantino VRL \& Faria DLA 1998. Spectroscopic study of cationic clays intercalated with tetramethylpyridylporphyrins. In: $21^{a}$ Reunião Anual da Sociedade Brasileira de Química, Poços de Caldas-Minas Gerais. Abstract QI-041, Vol. 1.

Lagaly G \& Beneke K 1991. Intercalation and Exchange Reactions of Clay Minerals and non-clay Layer Compounds. Colloid Polym Sci 269: 11981211.

Мотт CJB 1988. Clay Minerals - An Introduction. Catal Today 2: 199-208.

Ogawa M \& Kuroda K 1995. Photofunctions of Intercalation Compounds. Chem Rev 95: 399-438.

Rives V \& UlibarRi MA 1999. Layered Double Hydroxides (LDH) intercalated with metal coordination compounds and oxometalates. Coord Chem Rev 181: 61-120.

TRIFIRò F \& VACCARI A 1996. Hydrotalcite-like Anionic Clays (Layered Double Hydroxides). In: ALBERTI G \& BeIn T eds. Solid State Supramolecular Chemistry: Two and Three-Dimensional Inorganic Networks. New York, Pergamon, Vol. 7, Ch. 8, p.251-291.

Ukrainczyk L, Chibwe N, Pinnavaia TJ \& Boyd SA 1995. Reductive Dechlorination of Carbon Tetrachloride in Water Catalyzed by Mineral-supported Biomimetic Cobalt Macrocycles. Environ Sci Technol 29: 439-445. 